\title{
Intelligent Technology Helps Prevent and Control Outbreaks in Property Communities
}

\author{
Dongxiu Ye
}

\author{
College of Business Administration, Heyuan Polytechnic, Heyuan, Guangdong, China \\ Email id: Yedongxiu1988@163.com
}

\begin{abstract}
When Comrade Xi Jinping inspected the research on the prevention and control of new coronary pneumonia in Beijing, he emphasized that the most powerful weapon for humans to fight against diseases is science and technology, and that humankind cannot overcome major disasters without scientific development and technological innovation. Similarly, the intelligent management of the property management industry in the "war" epidemic has become an important means to help protect and solve the pain points. In order to meet the needs of owners and reduce the workload of employees, this paper summarizes the intelligent measures adopted by property management enterprises in epidemic prevention and anti-epidemic, and points out that the power of science and technology has made outstanding contribution to the realization of "zero contact service project" during the epidemic period.
\end{abstract}

Keywords: Smart facilities, Zero touch, Property management

\section{Introduction}

Since the outbreak of new coronapneumonia on the eve of the Spring Festival in 2020, the whole country has taken the next step to fight the disease. Treatment line is the hospital, prevention line is the property. Comrade $\mathrm{Xi}$ Jinping, President of the People's Republic of China, also stressed that "community is the first line of joint control of the epidemic, and it is also the most effective line of defense forexternal input and internal proliferation."[1] Thus, the property industry in the fight against the disease, plays a very critical role. In order to win this battle, the property should become a strong fortress for epidemic prevention and control.

Due to the spread characteristics of the new coronavirus, the property industry, which has long held the job, will also face certain risks of infection and understaffing pressure. In this context, the use of artificial intelligence technology, such as robots, in potentially dangerous contact scenes to help staff to undertake part of the work, become an efficient and safe means. This article summarizes the various types of intelligent facilities and equipment used by property management enterprises to meet the needs of owners and reduce the workload of employees and further reduce faceto-face contact with personnel during this outbreak, mainly in the following ten aspects.

\section{Intelligent Killing, to Ensure Security}

During the epidemic prevention and control period, the property area to carry out the epidemic killing work, to block the transmission of the virus channel, to curb the further development of the epidemic plays an important role. In order to protect the property's health and life safety, the property in addition to the use of killing staff to kill key areas, but also the use of a lot of intelligent equipment to assist in the killing work. Here's how:

(1) Elevator installation of ultraviolet disinfection lights. Ultraviolet disinfection lamp set has the human body sensing function, when people enter the elevator, UV disinfection lamp extinguished, will not shine on the human body; Viruses are sensitive to UV rays and heat and can effectively inactivate germs. [2]

(2) Drone disinfection. This disinfection method has a wider coverage, the realization of three-dimensional space killing, operational efficiency improvement, but also save human and material resources. [3]

(3) Medical-grade disinfection machine. In the walkway of the unit building, elevator to add a medical-grade disinfection machine, cleaning personnel every day to carry out regular frequency disinfection work, improve the safety factor of the owner in and out of the unit building.

(4) Remote intelligent inspection. Automatic identification of garbage overflow, timely notification of cleaning personnel as soon as possible to deal with, to avoid bacterial growth. [4]The principle is that through the camera exposure to the trash can, background algorithm analysis, effectively identify household waste and determine whether there is garbage overflow, when there is a garbage overflow in the public area, can be triggered by the AI system background warning work order, property personnel to the corresponding garbage drop point targeted cleaning. [5]

(5) Intelligent robot. The use of intelligent sweeping robot to clean the ground, the use of drones, fog gun vehicles, multi-functional flushing vehicles and other tools to kill, reduce the frequency of contact between cleaning personnel and the flow of people, reduce the chance of cross-infection, 
to ensure the safety of employees and customers, but also greatly reduce the work burden of cleaning staff. [6]

\section{Smart Shopping, Life Worry-Free}

During the epidemic, people everywhere actively respond to the call of the state, less out, do not string door, stay at home is to fight. However, due to the long duration of this "campaign", the people's living materials are generally in short supply. At this time, many property enterprises urgent owners, for owners to provide "basket" warm heart service, to take centralized food and daily necessities of service measures. To this end, the property enterprises implemented the "online order, offline distribution" interactive form for the owners to provide necessities of life. Owners in the community APP online to buy supplies for life, and notify the exclusive butler, that is, there are property personnel offline to provide door-to-door service. During the outbreak, the property service enterprises to do "put the door, turn around, zero contact"[7] service model, so that the owners can get goods without leaving the house. In addition to the manual door-to-door service provided by the staff of the property service enterprise, many communities have developed intelligent logistics robots to complete "contactless" distribution tasks. Staff only need to enter the order information, intelligent logistics robot scant route to avoid various obstacles on the road, after opening the door, call the elevator, take the ladder upstairs, and finally deliver the goods to the owner's door. Owners receive a service reminder from intelligent logistics robots, can be through face recognition, sweep code or input pickup code and other authentication methods to pick up goods. Owners do not need to be in contact with others throughout the distribution process, significantly reducing the risk of infection. [8]

\section{Intelligent Access, Fast Access}

Intelligent pass system is mainly composed of road gate, sidewalk gate and intelligent access control system, vehicles through "brushing", residents through "brushing face" or "swipe card" and other scientific and technological means to achieve automatic access. Among them, in the management of the road gate, the property management center can be in accordance with the needs, distinguish the set of the yard import and export pole rules, the use of multiangle combination camera, with AI identification, quick verification of vehicle information, to give stop-and-stop vehicles, non-monthly card vehicles, foreign license vehicles and other different access. During the outbreak, property management companies can easily identify and release owners and tenants, while tracking abnormal or isolated personnel vehicle sentry and exit conditions, staff do not use the yard patrol, but also to the dynamics of the car park. It not only guarantees the high-quality owner service experience, but also effectively reduces the cost of parking.
In the sidewalk gate, the community gate is a place with a large traffic, in order to avoid cross-infection, can use face recognition, mobile phone door opening and other noncontact intelligent pass equipment, can enable the owner to quickly pass, as far as possible to reduce the waiting time for inspection, to avoid congestion caused by crowding.

\section{Intelligent Temperature Measurement, Master Information}

Face recognition camera can effectively identify the identity of personnel, with infrared thermal imaging temperature measurement and personnel information library, not only can effectively prevent non-community owners from entering, but also can help property staff to grasp the first time the identity information of the owner of the abnormal temperature, to provide information support for follow-up. [9]

\section{Intelligent Services, Avoid Contact}

During the outbreak, the APP or WeChat program developed by property companies played an important role in order to avoid secondary cross-infection caused by human-to-human contact and human-to-object contact. Through the $\mathrm{O} 2 \mathrm{O}$ platform of diversified community life service, owners can enjoy a one-stop property service such as remote payment of property fees, reporting repair, mobile phone opening, complaint suggestions, etc., and also receive the outbreak prevention information, property announcement slot and other property information issued by the community, property and other departments through the platform, so as to achieve the owner's appeal online solution, so that the owner is relieved, rest assured, peace of mind. [10]

\section{Intelligent Troubleshooting, no Need to Meet}

During the epidemic, it is an important measure to prevent and control the epidemic to check the health situation and flow of the residents of the grass-roots community. In order to grasp the dynamic situation of the health of the community owners, some property enterprises use the online household check registration system. Residents of the owners entering and leaving the community are required to carry out a sweep, collect them uniformly by the management back office, summarize the data on a daily basis, and report it to the local police station. Since the implementation of online check-up registration, effectively avoid the problems of people stranded, human contact, form loss caused by filling out paper forms offline, at the same time, the effective screening of data has also improved the efficiency of the police station's anti-epidemic work docking. 


\section{Intelligent Propaganda, Deeply Rooted in the Hearts of the People}

In order to allow community residents to do a good job at home epidemic protection work, many property enterprises through the enterprise public number, community WeChat group, APP bulletin board and other platforms, the release of authoritative epidemic information and prevention and control measures. Some property enterprises use the wisdom of the big screen 24 hours a day rolling broadcast with the epidemic prevention and control related policies, knowledge, epidemic prevention tips and all kinds of announcements, notices and so on.

In addition, individual property companies also use robots in the park to do a good job of epidemic prevention publicity. By the robot reminded the owners to wear a good mask, try not to go out, prohibit non-community owners to enter the park work. [5]

\section{Intelligent Inspection, Avoid Gathering}

During the outbreak, in order to avoid the infection caused by the gathering of people, property enterprises are currently using two intelligent measures to carry out intelligent inspection, and in the first time to make action to discourage the gathering of people. On the one hand is the use of community cameras to patrol, if there are personnel gathered, the monitoring room timely [10]; to send work orders to the security guards on duty, rushed to the scene to persuade the personnel to disperse, on the other hand, by the robot in the park patrol process, identify the park has a gathering of personnel, will also be the first time feedback to the background, immediately there is order maintenance personnel to deal with.

There are also some community installation with interactive functions of the eye-catching cat camera device intelligent control system, the system at one end of the 24-hour panoramic scanning of the gate situation, one end of the link neighborhood committee, property companies, film police mobile phones and computers, when the door abnormal situation, managers can be through the mobile phone side in a timely manner to understand the details and put forward the corresponding handling comments. [11]

\section{Smart Consultation, Home-Based Medical Treatment}

Affected by the outbreak, many residents, even if they are unwell, do not dare to go to the hospital easily. To this end, a number of property enterprises from the perspective of community residents health, joint Spring Rain doctors, micro-doctors, ping An good doctors and Ali Health and other professional Internet medical consultation platform, open online 7 x 24 hours free consulting services, for owners to provide online consultation, medical advice, extremely quick consultation, owner care, and other services, so that owners can not attend professional diagnosis and treatment, timely understanding of their own health status, and can get online prescriptions, medicine and other services. [12]

\section{Smart Home, Healthy Body and Mind}

To help owners ease the tension during the outbreak and spend a lot of leisure time at home, many property companies have launched a variety of online community activities. By pushing all kinds of courses in mobile app, organizing online sports, online baking and online teaching, not only lead the owners to exercise to enhance personal resistance, but also greatly enrich the spiritual life of the "home" owners. [13]

The above ten aspects of intelligent services taken by property enterprises have played a very crucial role in the prevention and control of the current epidemic, which greatly enhances the comprehensive benefits of prevention and control. Property enterprises in this outbreak period has not adopted these intelligent measures, not only show the high-end of enterprise technology means, but also reflect the property services enterprises in the fight against the outbreak of social responsibility. This will also have a profound impact on the reputation of the property business. And after the outbreak, many enterprises also said that the property community will continue to implement intelligent systems, the current use of some emergency functions in the future will continue to serve the owners. With the power of the Internet and technology, and through digital management, "smart services" are likely to be a big step forward, driven by the outbreak.

\section{Conclusion}

The outbreak, for the country, is a test of the national governance system and governance capacity of a "big test", and for property companies, the same test of the strength of property enterprises. For the property industry, how to use the means of science and technology to build a more scientific, efficient, safe, healthy and convenient living environment, to achieve the property community with modern governance system and governance ability, will be an important direction of the future construction of intelligent community. [14]

\section{ACKNOWLEDGMENT}

This work was supported by 2019 Guangdong Province, the characteristic innovation project of ordinary colleges and universities, "Research on industrial concentration and spatial spillover effects in the Pearl River Delta region in the context of Guangdong, Hong Kong, Macao and The Great Bay Area" (2019GWTSCX097). 


\section{REFERENCES}

[1] Ruiming Luo. (2020) Prevent the rebound of the epidemic, and strictly guard the community defense line. http://www.chinanews.com/gn/2020/03-

02/9111347.shtml.

[2] Rongtao Weng, Yi Zhao. (2020) Community property's "anti-epidemic battle". China Business News

[3] Country Garden Service. (2020) Science and technology empowerment battle "epidemic", "hard core" property builds an invisible for the community. https://tech.ifeng.com/c/7u0cB8E4ZkO.

[4] Hui Zhong. (2020) At the time of the epidemic challenge, a new outlet for "real estate + " appeared. http://h520.cn/zixun/584.

[5] Jiahe Jiaye Property Service Research Institute. (2020) "China's Property Management Industry New Crown Prevention Guide (Community Residential Version) Version 2.0" is officially released!

https://mp.weixin.qq.com/s/Z8kFF1O1lpwtvyWXVkBp Aw.

[6] Luoqun Xie. (2020) Let the community become a strong bastion for epidemic prevention and control! https://mp.weixin.qq.com/s/71GID5zL2GI_Lv_H2wRW Qg.

[7] Luoqun Xie. (2020) Frontline Interview: Yida Service

Campaign.https://mp.weixin.qq.com/s/hf3xa9hSzIv6iY Th2sTbow

[8] Shunyu Yao. (2020) Technology escorts community epidemic prevention and control and industry development. China Construction News.

http://www.chinajsb.cn/html/202004/27/9713.html

[9] Zhongshan Zhang. (2020) A community defense battle in a capital state-owned enterprise. China Construction News.

[10] Tian Dong. (2020) Focus on scientific and technological innovation, return to work and fight against epidemic in Country Garden. China Securities News.

[11] Internet. (2020) Technology helps property companies, smart community security, peace of mind.

http://finance.ifeng.com/c/7txaIB8gVpk
[12] China Property Management Association. (2020) Science and technology warfare in epidemic communities. http://bas.qianjia.com/html/202002/15_360668.html

[13] Ran An. (2020) Property companies actively implement anti-epidemic measures to protect people's homes. Hainan Daily.

https://www.jianzhuj.cn/news/9154_2.html

[14] Shunyu Yao. (2020) Technology escorts community epidemic prevention and control and industry development. China Construction News.

http://www.chinajsb.cn/html/202004/27/9713.html 